\title{
Serum sclerostin in rheumatoid-induced osteoporosis
}

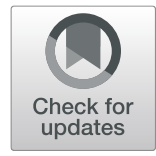

\author{
Ola Gharbia ${ }^{1 *}$ (D, Aliaa Hegazy ${ }^{1}$, Rania Elhelaly ${ }^{2}$ and Atif ElGhaweet ${ }^{1}$
}

\begin{abstract}
Background: Rheumatoid arthritis (RA) is characterized by presence of localized and generalized osteoporosis. The mechanism of decreased bone mass is complex and multifactorial, a possible mechanism behind increased bone loss in RA is upregulation of sclerostin. The aim of this work was to evaluate serum sclerostin level in RA patients and its relation with bone mineral density (BMD) and disease activity.

Results: Serum sclerostin level in RA patients was significantly higher than the controls $(p<0.001)$. Osteopenia and osteoporosis were more prevalent in RA patients (22.5\% and $7.5 \%$ respectively) compared to controls (15\% and $2.5 \%$ respectively) $(p=0.006)$. Serum sclerostin level was significantly correlated with tender joint count $(p=0.014)$, swollen joint count $(p=0.036)$, erythrocytes sedimentation rate $(p=0.010)$, $C$ reactive protein serum level $(p=$ $0.025)$, disease activity score (DAS) 28-ESR $(p=0.018)$, DAS28-CRP $(p=0.005)$, and radiological modified Sharp erosion score $(p=0.049)$. The correlation of serum sclerostin level in RA patients with BMD and with T-score in all sites revealed an inverse relationship with $p$ values insignificant.

Conclusion: Serum sclerostin is a major player in bone metabolism as a negative regulator of bone growth through inhibition of Wnt signaling that is largely influenced by the disease activity. Controlling the disease activity is a major factor for prevention of local as well as generalized osteoporosis and is essential for the reparative local and systemic bone health.
\end{abstract}

Keywords: Rheumatoid arthritis, Bone mineral density, Osteoporosis, Sclerostin

\section{Background}

Rheumatoid arthritis (RA) is a chronic inflammatory autoimmune disease characterized by chronic synovial inflammation with subsequent joint destruction and deformity [1]. Osteoporosis is more common in RA patients than in the general population [2]; with estimates revealed that approximately $32 \%$ and $26 \%$ of patients with longstanding RA had evidence of osteoporosis in lumbar spine and femoral neck respectively, almost twofold of the prevalence found in matched controls [3-5]. Interestingly, osteoporosis was observed in RA patients who were never exposed to corticosteroids, indicating that RA by itself is a significant risk factor for accelerated bone loss [6].

\footnotetext{
* Correspondence: dr_ola_gharbia@hotmail.com

'Physical Medicine, Rheumatology and Rehabilitation Department, Faculty of Medicine, Mansoura University, Mansoura, Egypt

Full list of author information is available at the end of the article
}

Sclerostin, encoded by SOST gene, is a glycoprotein secreted by osteocytes [7]. Sclerostin is upregulated during inflammation, interacts with low-density lipoprotein receptor-related protein 5/6 (LRP5/6), and displaces Wnt/ $\beta$-catenin proteins, hence, inhibits osteoblasts differentiation and proliferation $[8,9]$. Provided that RA is characterized by an increased rate of localized and generalized osteoporosis, it is hypothesized that the inflammatory background of the disease may contribute to the upregulation of sclerostin resulting in increased bone loss in RA.

However, studies investigated the association of sclerostin with RA had emerged conflicting results. For example, serum sclerostin levels had been reported to be significantly higher [10] or not statistically different [11] than the matched controls. Moreover, studies investigated the relationship between the sclerostin and bone 
loss in RA revealed controversial results as one study had demonstrated that elevated serum sclerostin levels in RA were not associated with bone loss [12] meanwhile another study observed that sclerostinneutralizing antibodies had prevented or decreased rate of bone mass loss in RA murine models [13]. Review of literature of some Egyptian studies done in psoriatic arthritis (PsA) and ankylosing spondylitis revealed that Sclerostin expression is impaired in early ankylosing spondyltis and was linked to disease activity [14], also it has been found that there is a significant role of sclerostin in the development of inflammation-associated bone damage in PsA [15].

In view of these conflicting data, the aim of this work is to evaluate serum sclerostin level in RA patients and its correlation with bone mineral density (BMD) and disease activity.

\section{Methods}

The present study included 40 RA patients recruited from the outpatient clinic of Rheumatology and Rehabilitation Department and 40 age- and sex-matched apparently healthy controls. The study was conducted in the period from June 2016 to January 2018. All patients fulfilled the 2010 American College of Rheumatology/ European League against Rheumatism classification criteria for RA [16]. Prior to inclusion, all participants were adequately informed about study aim and procedures in addition to be provided an informed written consent. The study was approved by the local ethics committee.

Subjects with other autoimmune diseases, secondary causes of osteoporosis (such as diabetes, celiac disease, and thyroid disease), vitamin D deficiency, chronic liver or kidney diseases, and those who were on medications that possibly alter BMD (e.g., estrogen, steroids, calcitonin, bisphosphonates, anticonvulsants, and thyroxin) were excluded from the study.

\section{Clinical assessment}

All participants enrolled in the study were subjected to full history taking and thorough clinical examination. The medical records of the RA patients were reviewed. Demographic characteristics including age, gender, body mass index (BMI) were obtained from all participants. History taking for RA patients included recording of duration of RA, medications and history suggestive of other autoimmune disorders. Clinical evaluation included the 28 tender (TJC) and swollen joint count (SJC), joint pain assessment on $100 \mathrm{~mm}$ visual analog scale (VAS-pain), assessment of functional disability using the health assessment questionnaire-disability index (HAQ-DI) score [17]. RA activity was assessed using the disease activity score 28 (DAS28) [18].

\section{Laboratory investigations}

Venous blood samples were withdrawn from all participants for the determination of serum sclerostin using enzyme-linked immunosorbent assay (ELISA) (TECO Medical $^{\circ}$, USA) following the manufacturer protocol. In RA patients, rheumatoid factor (RF) was measured by immuno-turbidimetry using Cobas Integra RFII (Roche Diagnostics $\mathrm{GmbH}$, Mannheim, Germany), and serum anti-cyclic citrullinated peptide (anti-CCP) antibodies were measured by ELISA kits (DIASTAT Axis-Shield, Dundee, UK) following the instructions of the manufacturer. $\mathrm{RF}$ values $>15 \mathrm{IU} / \mathrm{mL}$ and ACPA values $>20 \mathrm{IU} /$ $\mathrm{mL}$ were considered positive $[19,20]$. In addition, ESR by the Westergren method and $C$ reactive protein (CRP) were assessed in RA patients.

\section{Determination of bone mineral density}

For measurement of the BMD, the dual-energy X-ray absorptiometry (DEXA) scanning was done for all participants, using the GE Lunar Prodigy Primo Bone Densitometer, General Electric. All DEXA scans were performed by the same operator. The BMD values were presented as $\mathrm{g} / \mathrm{cm}^{2}$. Cutoffs of T-score were determined based on definitions of the World Health Organization [21].

\section{Plain radiography}

Plain radiographs for hands, wrists, and feet were performed for all patients. Radiological scoring was performed based on the modified Sharp erosion score [22].

\section{Statistical analysis}

All statistical calculations were done through the SPSS version 20.0 statistic software. All continuous data were normally distributed and were presented in mean \pm SD. Categorical data were presented in number and percentage. The comparisons were performed using independent sample Student's $t$ test for comparison between two variables with continuous data. Chi-square test was used for comparison of variables including categorical data. The 95\% confidence interval of mean difference for sclerostin serum level between patients and controls was calculated. Correlation coefficient test was used to explore the relationship between two continuous variables. Statistical significance was set at $p \leq 0.05$.

\section{Results}

General characteristics of patients and controls

As shown in Table 1, no significant difference is found between the RA group and the control group. Table 2 demonstrates the clinical, treatment, laboratory, and radiographic findings of RA patients. 
Table 1 The general characteristics of the RA patients and the controls

\begin{tabular}{lllll}
\hline & RA group & Control group & $P$ & S \\
\hline Age (years) & $46.7 \pm 13.6$ & $45.3 \pm 12.2$ & $0.629^{\#}$ & $0.576^{*}$ \\
Females $(n, \%)$ & $33,82.5 \%$ & $31,77.5 \%$ & $0.431^{*}$ & Insignificant \\
Post-menopausal females $(n, \%)$ & $16 / 40(40 \%)$ & $12 / 40(30 \%)$ & $0.878^{\#}$ & Insignificant \\
BMI (kg/m2) & $26.9 \pm 2.6$ & $26.8 \pm 2.7$ & $0.449^{*}$ & Insignificant \\
Family history of osteoporosis $(n, \%)$ & $6 / 40(15 \%)$ & $4 / 40(10 \%)$ & Insignificant \\
\hline
\end{tabular}

*X2 value, chi-square test

${ }^{\#} t$ value, Student $t$ test

\section{DEXA findings and serum sclerostin level in patients and controls}

The BMD at the lumbar spine region, neck of femur, and wrist were significantly lower in RA patients than controls; $p=0.016, p=0.020$, and $p=0.007$ respectively. In addition, $\mathrm{T}$-score of RA patients at the lumbar spine, neck of femur, and wrist were significantly lower than controls; $p=0.019, p<0.001$, and $p=0.007$ respectively (Table 3).

Serum sclerostin level in RA patients ranged between 0.37 and $0.54 \mathrm{ng} / \mathrm{ml}$ with a mean of $0.46 \pm 0.05$ $\mathrm{ng} / \mathrm{ml}$ meanwhile serum sclerostin level in controls ranged between 0.27 and $0.50 \mathrm{ng} / \mathrm{ml}$ with a mean of $0.37 \pm 0.06 \mathrm{ng} / \mathrm{ml}$. This difference was significant $(p<$ 0.001) (Table 3).

Table 2 The clinical, laboratory, radiographic, and treatment parameters of RA patients

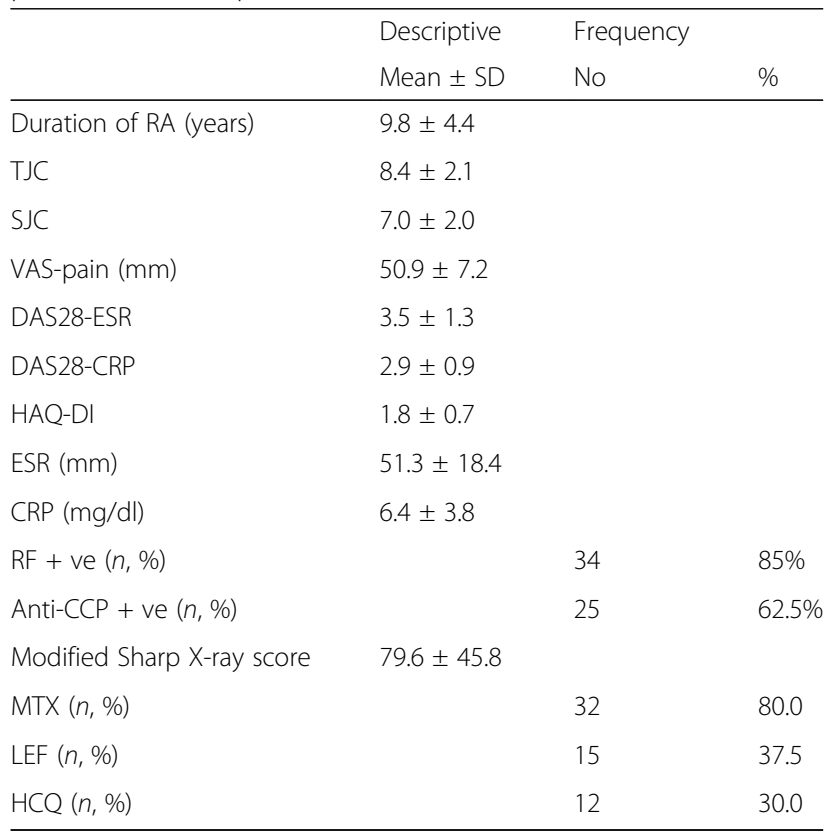

anti-CCP anti-cyclic citrullinated peptide, $C R P$ c-reactive protein, $D A S$ disease activity score, ESR erythrocyute sedminetation rate, $H A Q-D /$ health assessment questionnaire-disability index, HCQ hydroxycholoroquine, LEF leflunomide, MTX methotrexate, $R A$ rheumatoid arthritis, $R F$ rheumatoid factor, SWJ swollen joint count, TJC tendre joint count, VAS visual analog scale
In RA patients, $22.5 \%$ and $7.5 \%$ had osteopenia and osteoporosis respectively compared to $15 \%$ and $2.5 \%$ of controls had osteopenia and osteoporosis respectively. This difference was significant $(p=0.006)$ (Fig. 1).

\section{Relationship of serum sclerostin level with clinical and laboratory findings in the patients}

No significant association was observed between sclerostin serum level and sex, postmenopausal state, family history of osteoporosis, medications intake, RF positivity, nor anti-CCP positivity in RA patients (Table 4). No significant correlation was observed between serum sclerostin and age, BMI, duration of RA, duration of morning stiffness, HAQ-DI, or VAS-pain in RA patients as well (Table 5).

On the other hand, serum sclerostin level was significantly correlated with TJC $(p=0.014)$, SJC $(p=0.036)$, ESR $(p=0.010)$, CRP serum level $(p=0.025)$, DAS28ESR $(p=0.018)$, DAS28-CRP $(p=0.005)$. The correlation of serum sclerostin level in RA patients with the $\mathrm{BMD}$ and with $\mathrm{T}$-score in all sites revealed an inverse relationship, however, with $p$ values approaching but not reaching threshold of significance. Serum sclerostin level was significantly correlated with radiological modified Sharp erosion score $(p=0.049)$ (Table 5).

\section{Discussion}

The main findings of this study were (a) RA patients had significantly higher serum sclerostin level than controls; (b) serum sclerostin level in RA patients showed an inverse relationship with the BMD and with T-score in all sites, however, with $p$ values approaching but not reaching borderline of significance; (c) serum sclerostin level was significantly correlated with parameters with disease activity in RA patients; (d) serum sclerostin is significantly correlated with the modified Sharp X-ray score of joint damage in RA patients.

Prevalence of osteoporosis in RA patients varied greatly among studies. The previously reported prevalence of osteoporosis in RA patients was 22.0\% [23], $25.0 \%$ [24], 30.0\% [25, 26], 32.4\% [27], 40.4\% [28] while in one study it was as high as $79.8 \%$ [29]. In patients 
Table 3 Comparison of the DEXA findings and serum sclerostin level between the RA patients and the controls

\begin{tabular}{|c|c|c|c|c|}
\hline & RA group & Control group & $P$ & S \\
\hline \multicolumn{5}{|c|}{ Bone mineral density $\left(\mathrm{gm} / \mathrm{cm}^{2}\right)$} \\
\hline \multicolumn{5}{|l|}{ Lumbar spine } \\
\hline Range & $0.630-1.160$ & $0.700-1.290$ & & \\
\hline Mean \pm SD & $0.869 \pm 0.167$ & $0.966 \pm 0.183$ & 0.016 & Significant \\
\hline \multicolumn{5}{|c|}{ Neck of the femur } \\
\hline Range & $0.580-1.100$ & $0.640-1.210$ & & \\
\hline Mean \pm SD & $0.825 \pm 0.147$ & $0.908 \pm 0.162$ & 0.020 & Significant \\
\hline \multicolumn{5}{|l|}{ Wrist } \\
\hline Range & $0.440-1.060$ & $0.530-1.270$ & & \\
\hline Mean \pm SD & $0.731 \pm 0.213$ & $0.878 \pm 0.213$ & 0.007 & Significant \\
\hline \multicolumn{5}{|l|}{ T-score } \\
\hline \multicolumn{5}{|l|}{ Lumbar spine } \\
\hline Range & $-4.7--0.6$ & $-3.0--1.0$ & & \\
\hline Mean \pm SD & $-2.6 \pm 1.2$ & $-2.1 \pm 0.7$ & 0.019 & Significant \\
\hline \multicolumn{5}{|c|}{ Neck of the femur } \\
\hline Range & $-4.7--0.5$ & $-3.0--1.0$ & & Highly \\
\hline Mean \pm SD & $-2.7 \pm 1.3$ & $-1.9 \pm 0.7$ & $<0.001$ & Significant \\
\hline \multicolumn{5}{|l|}{ Wrist } \\
\hline Range & $-4.7--0.5$ & $-2.9--1.0$ & & \\
\hline Mean \pm SD & $-2.6 \pm 1.2$ & $-1.9 \pm 0.6$ & 0.007 & Significant \\
\hline \multicolumn{5}{|c|}{ Serum sclerostin level (ng/ml) } \\
\hline Range & $0.37-0.54$ & $0.27-0.50$ & & Highly \\
\hline Mean \pm SD & $0.46 \pm 0.05$ & $0.37 \pm 0.06$ & $<0.001$ & Significant \\
\hline
\end{tabular}

with recent-onset RA ( $<6$ months duration), osteoporosis was found in $25.0 \%$ of the patients [30]. The findings of this study supported the fact that RA patients had significantly lower BMD than healthy controls. In the present study, $30 \%$ of RA patients had low BMD (22.5\% had osteoporosis and 7.5\% had osteopenia).

A major finding of this study is that RA patients had a significantly higher sclerostin serum level than the controls. This finding comes in agreement with the findings of several previous studies [28, 29]. In Egypt, El-Bakry et al. [13] enrolled 31 RA patients ( 3 males and 28 females) and 10 healthy controls and reported significantly higher median serum sclerostin in RA patients than in controls a finding that is consistent with the findings of the present study.

In contrast, other studies reported no difference of serum sclerostin level between RA patients and controls $[12,31]$. This discrepancy can be attributed to the

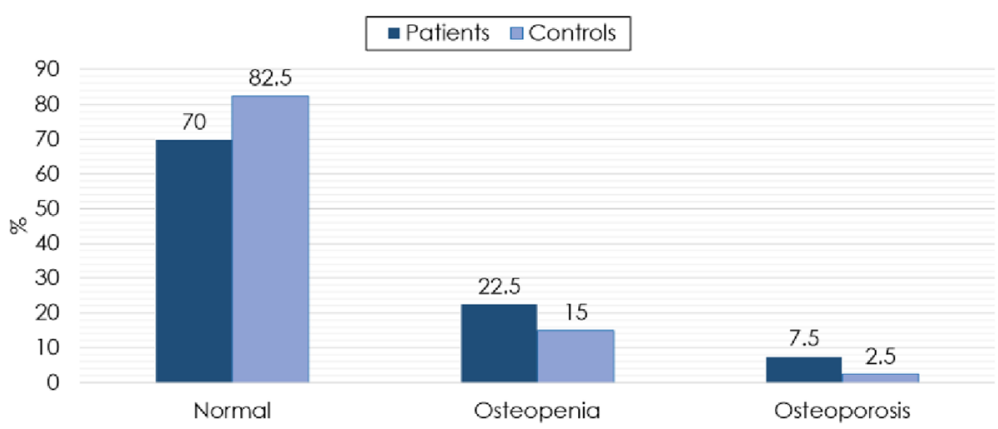

Fig. 1 The frequency of osteopenia and osteoporosis in RA patients and controls 
Table 4 The association of sclerostin serum level with sex, menopausal state, family history, drug intake, RF status, and anti-CCP status of RA patients

\begin{tabular}{|c|c|c|c|}
\hline \multirow[b]{2}{*}{ Sex } & \multicolumn{2}{|c|}{ Serum sclerostin level $(\mathrm{ng} / \mathrm{ml})($ mean $\pm \mathrm{SD})$} & \multirow{2}{*}{$\begin{array}{l}t \text { test }[P \\
0.146\end{array}$} \\
\hline & Females: $0.45 \pm 0.05$ & Males: $0.48 \pm 0.04$ & \\
\hline Postmenopausal & No: $0.44 \pm 0.05$ & Yes: $0.47 \pm 0.05$ & 0.073 \\
\hline Family history of osteoporosis & No: $0.45 \pm 0.05$ & Yes: $0.48 \pm 0.05$ & 0.183 \\
\hline MTX & No: $0.45 \pm 0.05$ & Yes: $0.47 \pm 0.05$ & 0.476 \\
\hline LEF & No: $0.47 \pm 0.05$ & Yes: $0.45 \pm 0.05$ & 0.273 \\
\hline $\mathrm{HCQ}$ & No: $0.46 \pm 0.05$ & Yes: $0.47 \pm 0.06$ & 0.933 \\
\hline RF & -ve: $0.45 \pm 0.05$ & +ve: $0.48 \pm 0.05$ & 0.183 \\
\hline Anti-CCP & -ve: $0.45 \pm 0.04$ & +ve: $0.48 \pm 0.06$ & 0.094 \\
\hline
\end{tabular}

In this table, for example in postmenopausal line, no means no postmenopausal state while yes means postmenopausal state and so on

anti-CCP anti-cyclic citrullinated peptide, HCQ hydroxycholoroquine, LEF leflunomide, MTX methotrexate, $R A$ rheumatoid arthritis, $R F$ rheumatoid factor

characteristics of the RA patients included in these two studies as most of the patients were in clinical remission or had low disease activity which indicates a very low degree of inflammation. Sclerostin expression is upregulated by proinflammatory cytokines during inflammation [9]. Sclerostin serum level depends on genetic factors,

Table 5 Correlation of the sclerostin serum level with age, BMI, and RA related features

\begin{tabular}{|c|c|c|}
\hline & $r$ & $P$ \\
\hline Age & 0.104 & 0.523 \\
\hline BMI & 0.051 & 0.754 \\
\hline Duration of RA & 0.076 & 0.640 \\
\hline Duration of morning stiffness & 0.098 & 0.546 \\
\hline TJC & 0.375 & 0.014 \\
\hline SJC & 0.333 & 0.036 \\
\hline VAS-pain & 0.114 & 0.483 \\
\hline HAQ-DI & 0.255 & 0.113 \\
\hline ESR & 0.404 & 0.010 \\
\hline CRP & 0.354 & 0.025 \\
\hline DAS28-ESR & 0.371 & 0.018 \\
\hline DAS28-CRP & 0.438 & 0.005 \\
\hline Modified Sharp X-ray score & 0.314 & 0.049 \\
\hline \multicolumn{3}{|l|}{$\mathrm{BMD}\left(\mathrm{gm} / \mathrm{cm}^{2}\right)$} \\
\hline Lumbar spine & -0.301 & 0.059 \\
\hline Neck of the femur & -0.299 & 0.061 \\
\hline Wrist & -0.297 & 0.063 \\
\hline \multicolumn{3}{|l|}{ T-score } \\
\hline Lumbar spine & -0.305 & 0.056 \\
\hline Neck of the femur & -0.302 & 0.058 \\
\hline Wrist & -0.290 & 0.069 \\
\hline
\end{tabular}

CRP c-reactive protein, DAS disease activity score, ESR erythrocyute sedminetation rate, $H A Q-D I$ health assessment questionnaire-disability index, $R A$ rheumatoid arthritis, SWJ swollen joint copunt, TJC tendre joint count, VAS visual analog scale age, sex, adiposity, kidney function, and presence of diabetes mellitus which may account for the discrepancy of the results among the studies [32].

Mehaney et al. [33] studied 40 RA Egyptian patients (12 males and 28 females) with an average age of $48.9 \pm$ 11.6 years and 40 healthy controls and found no significant difference of serum sclerostin level between RA patients compared to controls. This difference may be explained by the differences in the study population as > $62 \%$ of the females in the control group in their study were postmenopausal compared to $38.7 \%$ in our study.

In the current study, no association had been found between sclerostin serum level with age, sex, or menopausal state. These findings were consistent with results of previous studies [33-36].

Regarding the association between serum sclerostin concentration and RA activity indices, the previous studies revealed conflicting results. The present study showed that serum sclerostin level was significantly correlated with indices of disease activity, which comes in agreement with findings of a previous study on Egyptian patients [37]. Moreover, Brabnikova-Maresova et al. [38] reported that serum sclerostin level is significantly correlated with TJC, CRP, and DAS in juvenile patients with RA. The authors of that study concluded that the association between RA activity indices and serum sclerostin levels indicate inhibition of new bone formation during active inflammation process in juvenile idiopathic arthritis patients. Conversely, El-Bakry et al. [13] found that serum sclerostin level was significantly correlated with TJC but inversely correlated with CRP and DAS.

In the present study, serum sclerostin level showed a significant correlation with the radiological score. ElBakry et al. [13] and Ibrahim et al. [37] reported significant positive correlation between serum sclerostin and modified Larsen score while Eissa el al [11]. and Mehaney et al. [34] reported no significant correlation between serum sclerostin and radiological grading. This 
discrepancy can be explained by the different radiological scores chosen. The correlation between the serum sclerostin level and erosion score seems reasonable. Impaired repair of bone erosion in RA can be attributed to mechanisms that inhibit new bone formation. Upregulation of sclerostin, the Wnt antagonist, is enhanced during inflammation leading to suppression of repair of bone erosions [39]. Blocking of Wnt antagonists by sclerostin may induce repair or even healing of bone erosions [12].

Several studies assessed the relationship between serum sclerostin level and BMD and the T-score at lumbar spine and at the neck of femur had found conflicting results. In one hand, Mehaney et al. [33] found that although the serum sclerostin level was higher in RA patients with low BMD in comparison to those with normal BMD, these differences were statistically insignificant. On the other hand, other studies found that serum sclerostin is inversely correlated with BMD in healthy and osteoporotic women [40, 41]. Moreover, it was previously reported that sclerostin serum level is positively correlated with BMD at the lumbar spine [31] and at the neck of the femur [38]. In the present study, serum sclerostin level in RA patients had an inverse relationship with the BMD and with $\mathrm{T}$-score in all sites with $p$ values approaching but did not reach threshold of significance, in agreement with the results of Mehaney et al. [33].

In two studies by Ardawi et al. [40, 41], who observed an inverse significant correlation between the serum sclerostin level and the BMD, all enrolled women were pre- and post-menopausal healthy (non-RA) women in one study and in the other study all enrolled women were postmenopausal which may account for the discrepancy from the current study. On the other hand, the positive association between BMD and serum sclerostin is difficult to explain, however, Paccou et al. [31] suggested that the sclerostin level may simply reflect the bone mass and the number of active osteocytes.

More studies on sclerostin, in larger RA population, are required for better discrimination of role of sclerostin in patients with RA. In addition, it will be necessary to determine whether anti-sclerostin antibodies could slow the progression of bone mineral loss in RA patients.

\section{Conclusion}

Serum sclerostin is a major player in bone metabolism as a negative regulator of bone growth through inhibition of Wnt signaling that is largely influenced by the disease activity. Controlling the disease activity is a major factor for prevention of local as well as generalized osteoporosis and is essential for the reparative local and systemic bone health. More follow-up longitudinal studies are recommended to detect the effect of control of disease activity on serum sclerostin and the validity of this serum marker to reflect bone health in RA patients.

\section{Abbreviations}

Anti-CCP: Serum anti-cyclic citrullinated peptide; BMD: Bone mineral density; BMI: Body mass index; CRP: C reactive protein; DAS: Disease activity score; DEXA: Dual-energy X-ray absorptiometry; ELISA: Enzyme-linked

immunosorbent assay; HAQ-DI: Health assessment questionnaire-disability index; LRP5/6: Lipoprotein receptor-related protein 5/6; PSA: Psoriatic arthritis; RA: Rheumatoid arthritis; RF: Rheumatoid factor; SJC: Swollen joint count; TJC: Tender joint count

\section{Acknowledgements}

Not applicable

\section{Authors' contributions}

OG analyzed and interpreted the patients' data, contributed in performing statistical analysis of the results and major contribution in writing manuscript. AH contributed in analyzing and interpreting of patients' data and performing statistical analysis. RE was responsible for performing all laboratory tests present in the study. AE contributed in writing the manuscript. All authors read and approved the final manuscript.

\section{Funding}

No funding

\section{Availability of data and materials}

The datasets used and/or analyzed during the current study are available from the corresponding author on reasonable request.

\section{Ethics approval and consent to participate}

The research was approved by Institutional Research Board (IRB) of Mansoura University with code number: MS/16.03.53 by date: 22/3/2016 and the written consent was obtained from all participants and approved by IRB.

Consent for publication

Not applicable in this study as there are no personal details.

\section{Competing interests}

The authors declare that they have no competing interests.

\section{Author details}

${ }^{1}$ Physical Medicine, Rheumatology and Rehabilitation Department, Faculty of Medicine, Mansoura University, Mansoura, Egypt. ${ }^{2}$ Clinical Pathology Department, Faculty of Medicine, Mansoura University, Mansoura, Egypt.

Received: 22 April 2020 Accepted: 18 May 2020

Published online: 29 July 2020

\section{References}

1. Guo Q, Wang Y, Xu D, Nossent J, Pavlos NJ, Xu J (2018) Rheumatoid arthritis: pathological mechanisms and modern pharmacologic therapies. Bone Res 6:15

2. Heinlen L, Humphrey MB (2017) Skeletal complications of rheumatoid arthritis. Osteoporos Int 28(10):2801-2812

3. Haugeberg G, Uhlig T, Falch JA, Halse II, Kvien TK (2000) Bone mineral density and frequency of osteoporosis in female patients with rheumatoid arthritis: results from 394 patients in the Oslo County Rheumatoid Arthritis register. Arthritis Rheum 43:522-530

4. Haugeberg G, Uhlig T, Falch JA, Halse Jl, Kvien TK (2000) Reduced bone mineral density in male rheumatoid arthritis patients: frequencies and associations with demographic and disease variables in ninety-four patients in the Oslo County Rheumatoid Arthritis Register. Arthritis Rheum 43:27762784

5. Hauser B, Riches PL, Wilson JF, Horne AE, Ralston SH (2014) Prevalence and clinical prediction of osteoporosis in a contemporary cohort of patients with rheumatoid arthritis. Rheumatology (Oxford) 53(10):1759-1766

6. van Staa TP, Geusens P, Bijlsma JW, Leufkens HG, Cooper C (2006) Clinical assessment of the long-term risk of fracture in patients with rheumatoid arthritis. Arthritis Rheum 54:3104-3112 
7. Moester MJ, Papapoulos SE, Löwik CW, van Bezooijen RL (2010) Sclerostin: current knowledge and future perspectives. Calcif Tissue Int 87(2):99-107

8. Baron R, Rawadi G (2007) Minireview: targeting the Wnt/ $\beta$-catenin pathway to regulate bone formation in the adult skeleton. Endocrinology 148(6): 2635-2643

9. Delgado-Calle J, Sato AY, Bellido T (2017) Role and mechanism of action of sclerostin in bone. Bone 96:29-37

10. El-Bakry S, Saber N, Zidan H, Samaha D (2016) Sclerostin as an innovative insight towards understanding Rheumatoid Arthritis. Egypt Rheumatol 38(2): 71-75

11. Vargas-Muñoz VM, Jimenez-Andrade MC, Villarreal-Salcido JC, MartinezMartinez A, Acosta-Gonzalez Rl, Lugo-Zamudio GE, et al. (2015) Association between sclerostin and bone mineral density in a Mexican sample of women with rheumatoid arthritis: A pilot study. J Arthritis S1:S1-008.

12. Eissa M, Anwar S, Fakhreldin S, Mehaney D (2014) Serum sclerostin level among Egyptian rheumatoid arthritis patients: relation to bone mineral density, disease activity and radiological grading. Ann Rheum Dis 73(Suppl. 2):893-894

13. Marenzana M, Vugler A, Moore A, Robinson M (2013) Effect of sclerostinneutralising antibody on periarticular and systemic bone in a murine model of rheumatoid arthritis: a microCT study. Arthritis Res Ther 15(5):R125

14. Enas EAA, Dina FA, Reem EME, Dalia SY (2017) Study of serum sclerostin levels in association to entheseal ultrasonography in Egyptian psoriatic arthritis patients. Egypt Rheumatol Rehabil 44:45-51

15. Manal A, Nassar WA, El Sherbeny AA, Escandar RT (2013) Bone mineral density and serum sclerostin levels in early ankylosing spondylitis: their possible correlation with a panel of disease activity and structural change parameters.Egypt. Rheumatol Rehabil 40(2):81-87

16. Aletaha D, Neogi T, Silman AJ, Funovits J, Felson DT, Bingham CO 3rd et al (2010) 2010 rheumatoid arthritis classification criteria: an American College of Rheumatology/European League Against Rheumatism collaborative initiative. Ann Rheum Dis 69(9):1580-1588

17. Bruce B, Fries J (2003) The Stanford Health Assessment Questionnaire: a review of its history, issues, progress, and documentation. J Rheumatol 30(1):167-178

18. Prevoo ML, van 't Hof MA, Kuper HH, van Leeuwen MA, van de Putte LB, van Riel PL (1995) Modified disease activity scores that include twentyeight-joint counts. Development and validation in a prospective longitudinal study of patients with rheumatoid arthritis. Arthritis Rheum 38(1):44-48

19. Santos-Moreno P, Sánchez G, Castro C (2019) Rheumatoid factor as predictor of response to treatment with anti-TNF alpha drugs in patients with rheumatoid arthritis: Results of a cohort study. Medicine (Baltimore) 98(5):e14181

20. Silveira IG, Burlingame RW, von Mühlen CA, Bender AL, Staub HL (2007) Anti-CCP antibodies have more diagnostic impact than rheumatoid factor (RF) in a population tested for RF. Clin Rheumatol 26(11):1883-1889

21. World Health Organization (2004) WHO scientific group on the assessment of osteoporosis at primary health care level. WHO

22. van der Heijde D (1999) How to read radiographs according to the Sharp/ van der Heijde method. J Rheumatol 26(3):743-745

23. Shankar S, Handa R, Aneja R, Marwaha V, Ammini AC, Aprajita V (2009) Bone mineral density in Indian women with rheumatoid arthritis. Rheumatol Int 29:377-381

24. Dhakad U, Sahoo R, Goel A, Pradhan S, Srivastava R, Das S (2019) Serum sclerostin levels in rheumatoid arthritis and correlation with disease activity and bone mineral density. Indian J Rheumatol 14(1):28-31

25. Gauri LA, Fatima Q, Diggi S, Khan A, Liyakat A, Ajay BR (2017) Study of bone mineral density (BMD) in patients with rheumatoid arthritis and its corelation with severity of the disease. J Assoc Physicians India 65(4):26-30

26. Cheng T, Yu S, Su F, Chen Y, Su B, Chiu W et al (2018) Anti-CCP-positive patients with RA have a higher 10-year probability of fracture evaluated by FRAX ${ }^{\circledR}$ : a registry study of RA with osteoporosis/fracture. Arthritis Res Ther 20:16

27. Mobini M, Kashi Z, Ghobadifar A (2012) Prevalence and associated factors of osteoporosis in female patients with rheumatoid arthritis. Caspian J Intern Med 3(3):447-450

28. Ghozlani I, Mounach A, Ghazi M, Kherrab A, Niamane R, El Maghraoui A (2018) Influence of anti-cyclic citrullinated peptide on disease activity, structural severity, and bone loss in Moroccan women with rheumatoid arthritis. Egypt Rheumatol 40(2):73-78
29. Wafa H, Raja A, Dhia K, Nada B, Kchir Z, Montacer M (2019) Risk factors associated with bone loss and occurrence of fragility fractures in rheumatoid arthritis patients. Egypt Rheumatol 41(1):1-5

30. Arain SR, Riaz A, Nazir L, Umer TP, Rasool T (2016) Low bone mineral density among patients with newly diagnosed rheumatoid arthritis. J Ayub Med Coll Abbottabad 28(1):175-178

31. Paccou J, Mentaverri R, Renard C, Liabeuf S, Fardellone P, Massy ZA et al (2014) The relationships between serum sclerostin, bone mineral density, and vascular calcification in rheumatoid arthritis. J Clin Endocrinol Metab 99(12):4740-4748

32. Kuipers AL, Zhang Y, Yu S, Kammerer CM, Nestlerode CS, Chu Y et al (2014) Relative influence of heritability, environment and genetics on serum sclerostin. Osteoporos Int 25:905-912

33. Mehaney DA, Eissa M, Anwar S, Fakhr E-DS (2015) Serum sclerostin level among Egyptian rheumatoid arthritis patients: relation to disease activity, bone mineral density and radiological grading. Acta Reumatol Port 40(3): 268-274

34. Mirza FS, Padhi ID, Raisz LG, Lorenzo JA (2010) Serum sclerostin levels negatively correlate with parathyroid hormone levels and free estrogen index in postmenopausal women. J Clin Endocrinol Metab 95:1991-1997

35. Gennari L, Merlotti D, Valenti R et al (2012) Circulating sclerostin levels and bone turnover in type 1 and type 2 diabetes. J Clin Endocrinol Metab 97(5): 1737-1744

36. Polyzos S, Anastasilakis D, Bratengeier C, Woloszczuk W, Papatheodorou A Terpos E (2012) Serum sclerostin levels positively correlate with lumbar spinal bone mineral density in postmenopausal women-the six-month effect of risedronate and teriparatide. Osteoporos Int 23(3):1171-1176

37. Ibrahim S, Abdelsamad A, Helmy A, Farouk N (2015) Serum sclerostin levels in rheumatoid arthritis. Indian J Rheumatol 10:117-120

38. Brabnikova-Maresova K, Jarosova K, Pavelka K, Stepan JJ (2014) Serum sclerostin in high-activity adult patients with juvenile idiopathic arthritis. Arthritis Res Ther 16(5):460

39. Matzelle MM, Gallant M, Condon KW, Walsh NC, Manning CA, Stein GS et al (2012) Resolution of inflammation induces osteoblast function and regulates the Wnt signaling pathway. Arthritis Rheum 64(5):1540-1550

40. Ardawi MS, Rouzi AA, Al-Sibiani SA, Al-Senani NS, Qari MH, Mousa SA (2012) High serum sclerostin predicts the occurrence of osteoporotic fractures in postmenopausal women: the Center of Excellence for Osteoporosis Research Study. J Bone Miner Res 27(12):2592-2602

41. Ardawi MS, Al-Kadi HA, Rouzi AA, Qari MH (2011) Determinants of serum sclerostin in healthy pre- and postmenopausal women. J Bone Miner Res 26(12):2812-2822

\section{Publisher's Note}

Springer Nature remains neutral with regard to jurisdictional claims in published maps and institutional affiliations.

\section{Submit your manuscript to a SpringerOpen ${ }^{\circ}$ journal and benefit from:}

- Convenient online submission

- Rigorous peer review

- Open access: articles freely available online

High visibility within the field

- Retaining the copyright to your article

Submit your next manuscript at $>$ springeropen.com 